\title{
Factors Affecting Mechanical Transmission of Tomato spotted wilt virus to Peanut (Arachis hypogaea)
}

\author{
B. Mandal, H. R. Pappu, and A. K. Culbreath, Department of Plant Pathology, University of Georgia, Coastal \\ Plain Experiment Station, Tifton 31793
}

\section{ABSTRACT}

Mandal, B., Pappu, H. R., and Culbreath, A. K. 2001. Factors affecting mechanical transmission of Tomato spotted wilt virus to peanut (Arachis hypogaea). Plant Dis. 85:1259-1263.

Evaluation of peanut germ plasm for Tomato spotted wilt virus (TSWV) resistance has been slowed by the difficulty in achieving a high rate of mechanical transmission of the virus to peanut. In this study, improvements were made and a highly efficient mechanical transmission protocol was developed. Several factors that affect the transmission efficiency were identified. Use of two antioxidants (sodium sulfite and mercaptoethanol) and two abrasives (Celite and Carborundum) and application of the inoculum by rubbing with a cotton swab dipped in the inoculum as well as pricking with an inoculation needle resulted in a significantly higher transmission rate. The most susceptible growth stage of peanut to TSWV inoculation was 2 to 3 days after germination (6 to 7 days after planting). The inoculation protocol consistently resulted in a higher percentage of infected plants from different sources of inoculum such as infected peanut, tobacco, and tomato.

Additional keywords: Bunyaviridae, Georgia Runner, groundnut, host plant resistance, Tospovirus

Tomato spotted wilt virus (TSWV) is the type member of the genus Tospovirus in the family Bunyaviridae (13). TSWV is a serious plant pathogen affecting several important crop plants throughout the world (15). In the southern United States, peanut or groundnut (Arachis hypogaea L.) is severely affected by TSWV $(1,4,10,11,18)$. Losses due to TSWV in peanut were estimated at several millions of dollars in Georgia alone (22). In peanut, TSWV induces a wide range of symptoms. Foliar symptoms include chlorotic spots, chlorotic streaks, mosaic, ring spots, concentric rings, necrotic spots, and yellowing. Plants infected at an early stage are often severely stunted, resulting in serious yield losses $(4,11)$.

TSWV is transmitted by thrips in a persistent manner (8). Western flower thrips (Frankliniella occidentalis) and tobacco thrips (F. fusca) are the major vectors associated with TSWV epidemics in peanut in Georgia (19,20). Insecticidal applications to control thrips are largely ineffective in reducing TSWV in peanut $(19,20)$. Growing resistant cultivars has been an impor-

Corresponding author: H. R. Pappu

E-mail: hanu.r.pappu@aphis.usda.gov

Present address of H. R. Pappu: USDA-APHIS, Unit 147, 4700 River Road, Riverdale, MD 20737.

Accepted for publication 24 August 2001.

Publication no. D-2001-1019-02R

(C) 2001 The American Phytopathological Society tant tactic for managing this disease. Several new cultivars with field resistance to TSWV are available, and more are in various stages of development (4-6).

Recently, the impact of TSWV in Georgia's peanut crop has been reduced by integration of a multiple factor management program. The central thrust of the program has been the use of resistant cultivars such as Georgia Green, Virugard, and MDR98 (2). Breeding for resistance to TSWV is based on the performance of breeding lines under natural occurrence of the disease in the field. Under field conditions, all plants may not be exposed to thrips-borne TSWV inoculum. Therefore, the level of true resistance cannot be assessed based on only field observations.

Successful inoculation of TSWV to individual plants by mechanical methods or vectors are necessary to evaluate the level of resistance in a genotype to be used in breeding programs. Availability of a highly efficient method for mechanical transmission would enable such screening and would facilitate quick identification of sources of TSWV resistance. Previous reports $(3,12,16)$ utilized standard inoculation procedures to transmit TSWV to peanut. Most of these methods involved maintaining TSWV in Nicotiana benthamiana. We report a protocol that ensures efficient and reliable mechanical transmission of TSWV to peanut.

\section{MATERIALS AND METHODS}

Source of viral inocula. Leaves of Nicotiana tabacum showing typical symptoms of TSWV were collected from Black
Shank Nursery at the Coastal Plain Experiment Station, University of Georgia, Tifton. Three kinds of tobacco leaves were collected from the field, (I) top tender leaves showing development of necrosis, (II) top tender leaves that showed no symptoms, even though the lower leaves of the same plants had TSWV symptoms, and (III) mature leaves showing necrosis. TSWV infection of these samples was confirmed by enzyme-linked immunosorbent assay (ELISA) using a kit from Agdia Inc. (Elkhart, IN). Inocula were prepared by grinding $3 \mathrm{~g}$ each of the above samples separately in $18 \mathrm{ml}$ of $0.1 \mathrm{M}$ phosphate buffer, pH 7.0, containing $0.1 \% \mathrm{Na}_{2} \mathrm{SO}_{3}$. A total of 24,25 , and 30 peanut seedlings grown in the greenhouse were inoculated by rubbing with each category of inoculum sources, I, II, and III, respectively. The inoculated plants were kept in the greenhouse (temperature: minimum $21^{\circ} \mathrm{C}$ and maximum $45^{\circ} \mathrm{C}$, relative humidity: 16 to $80 \%$, light intensity: 26 to $92 \mathrm{klx}$ ) and observed daily for symptoms expression. TSWV infection in the peanut was confirmed by ELISA, and the viral culture was maintained in peanut in a growth chamber. All the inoculation studies to evaluate various factors influencing mechanical transmission to peanut were performed in the growth chamber using the above TSWV culture maintained on peanut.

Raising of test plants. Georgia Runner, a previously popular runner-type peanut cultivar that is susceptible in the field to TSWV, was used to evaluate the inoculation procedure. Test plants were grown in an environmental growth chamber at 28 to $30^{\circ} \mathrm{C}, 60$ to $80 \%$ relative humidity $(\mathrm{RH})$ during a 12-h light period (a light intensity of 12 to $15 \mathrm{klx}$ ) and 85 to $95 \% \mathrm{RH}$ during a 12-h dark period. Five to eight seeds were planted in each plastic pot $(16 \mathrm{~cm}$ diameter and $14 \mathrm{~cm}$ high) containing all purpose professional growing mix consisting of Canadian sphagnum peat moss 75 to $85 \%$, perlite 15 to $20 \%$, and vermiculite 5 to $10 \%$ (Berger Peat Moss-Lee Berger Itee, Saint-Modeste, Quebec, Canada). Seedlings with uniform growth were then selected and transplanted into new pots.

Inoculum preparation. Freshly infected tissue was prechilled on ice and ground (1:6 [wt/vol] tissue:buffer) with freshly prepared ice-cold $0.01 \mathrm{M}$ potassium phosphate buffer, $\mathrm{pH} 7.0$, containing $0.2 \%$ sodium sulfite and 0.01 M 2-mercaptoethanol using a chilled pestle and mortar. Debris was removed by squeezing the 
ground extract through a pad of nonabsorbent cotton. To this sap, Celite 545 (Fisher Scientific, Fair Lawn, NJ) and Carborundum 320 grit (Fisher Scientific) were $2 \%$, respectively. The sap was kept on ice till the inoculation was completed.

Methods of sap inoculation. Inoculum was prepared as described above. In addition to adding Carborundum in the inoculum, test plants were also dusted with Carborundum 5 to 7 days after planting (DAP). Three methods of inoculation were compared, (I) pricking, (II) rubbing, and (III) rubbing and pricking (Table 1). In the rubbing method, Johnson's cotton swabs (Johnson \& Johnson, Skillman, NJ) were dipped in the inoculum and rubbed on both surfaces of the leaves. In the pricking method, inoculation was done by using an inoculating needle, which was prepared by assembling six stainless steel insect pins, size A '000' on a metal holder (Bio Quip Products Inc., Gardena, CA). A drop of inoculum was placed on the terminal buds of the main shoot and two auxiliary shoots at the base of the cotyledons, and two prickings were made on each side of the shoots with the inoculation needle. After inoculation, the plants were sprayed with distilled water and kept in the growth chamber under a low light intensity of about $1,000 \mathrm{~lx}$, or inoculation was done in the evening and plants were kept in the dark at $28^{\circ} \mathrm{C}$ and 80 to $95 \% \mathrm{RH}$ for about $16 \mathrm{~h}$. Thereafter, the inoculated plants were kept under a light intensity of 15 to $20 \mathrm{klx}$, 27 to $30^{\circ} \mathrm{C}, 60$ to $95 \% \mathrm{RH}$, and alternating light and dark periods of $12 \mathrm{~h}$ each.

Determination of effect of antioxidants, abrasives, and growth stages of peanut on transmission. To determine the inocula were prepared by grinding $3 \mathrm{~g}$ each of infected peanut tissue using $18 \mathrm{ml}$ each of (I) sterile distilled water, (II) $0.1 \mathrm{M}$ potassium phosphate buffer, $\mathrm{pH} 7$, (III) phosphate buffer containing $0.2 \%$ sodium sulfite, and (IV) phosphate buffer containing $0.2 \%$ sodium sulfite and $0.01 \mathrm{M}$ mercaptoethanol. Seven-day-old plants were inoculated by the rubbing and pricking method using Carborundum and Celite as described above. In the first trial, eight added to a final concentration of $1 \%$ and effect of antioxidant, four categories of

plants were inoculated for each category of inoculum, and thereafter two more trials were conducted, inoculating 10 plants for each category of inoculum.

To evaluate the role of two abrasives, Carborundum and Celite, on the rate of transmission, sap was prepared (1:6 [wt/vol] tissue:buffer) in phosphate buffer containing $0.2 \%$ sodium sulfite and $0.01 \mathrm{M}$ mercaptoethanol. This extract was divided into three parts, wherein (I) only Carborundum 320 grit (2\%), (II) only Celite 545 (1\%), and (III) both Carborundum (2\%) and Celite $(1 \%)$ were added. In addition, Carborundum also was sprinkled over the 7-day-old test plants to be inoculated with inocula I and III. No Carborundum was sprinkled over the test plants or added to the inoculum II, where the effect of Celite alone on transmission was studied. The number of plants inoculated, replications, and the methods of inoculation were the same as mentioned above in the case of evaluation of antioxidants.

To evaluate the effect of growth stages on the susceptibility of peanut to TSWV, eight test plants in each of the three trials were inoculated by rubbing and pricking at (I) 5 DAP, that is, after germination and before opening of folded lamina, (II) 6 to 7 DAP, after opening the folded lamina of the first pair of quadrifoliates, (III) 15 DAP, before flowering, and (IV) 35 DAP, after flowering. All the lower leaves of the plants inoculated at 15 or 35 DAP were removed, and only the topmost quadrifoliate was inoculated. Inoculum was prepared by grinding peanut tissue in phosphate buffer (1:6 wt/vol) containing $0.2 \%$ sodium sulfite and $0.01 \mathrm{M}$ mercaptoethanol, and both Carborundum and Celite were used as abrasives in the inoculum.

Incubation days (number of days between inoculation and symptom expression) were compared with the plant ages. At any plant age, final date of symptom appearance varied in the three inoculation trials. Therefore, average incubation days at final disease incidence was taken into consideration for comparison with plant ages.

Symptom observation, TSWV detection, and statistical analysis. Inoculated plants were observed daily for symptom development. In a single set of inoculated

Table 1. Mechanical transmission of Tomato spotted wilt virus to peanut by different methods

\begin{tabular}{|c|c|c|c|c|c|}
\hline \multirow[b]{2}{*}{ Method $^{\mathrm{x}}$} & \multicolumn{3}{|c|}{$\begin{array}{l}\text { No. of symptomatic plants/ } \\
\text { no. of inoculated plants }\end{array}$} & \multirow[b]{2}{*}{$\operatorname{Mean}^{z}$} & \multirow{2}{*}{$\begin{array}{l}\text { Days post- } \\
\text { inoculation }\end{array}$} \\
\hline & $\mathbf{I}^{\mathbf{y}}$ & II & III & & \\
\hline Pricking & $1 / 10$ & $1 / 8$ & $6 / 10$ & $27.0 \mathrm{a}$ & $8-11$ \\
\hline Rubbing & $7 / 10$ & $6 / 6$ & $7 / 9$ & $82.3 \mathrm{~b}$ & $6-10$ \\
\hline $\begin{array}{c}\text { Rubbing + } \\
\text { pricking }\end{array}$ & $10 / 10$ & $8 / 8$ & $9 / 10$ & $96.6 \mathrm{c}$ & $6-10$ \\
\hline
\end{tabular}

x Plants (5 to 7 days old) were inoculated using $0.1 \mathrm{M}$ phosphate buffer, $\mathrm{pH} 7.0$, containing $0.2 \%$ $\mathrm{Na}_{2} \mathrm{SO}_{3}$ and $0.01 \mathrm{M}$ mercaptoethanol. Carborundum (2\%) and Celite (1\%) were added to the inoculum.

$\mathrm{y}$ Inoculation trials.

${ }^{\mathrm{z}}$ Means marked with different letters are significantly different from each other at $P=0.05$ according to Duncan's multiple range test. plants, all plants did not produce symptoms at the same day postinoculation (DPI); some took longer to develop symptoms than others. Inoculated plants were kept in the growth chamber for a month after inoculation, and the date on which symptoms were observed on each plant was recorded. All plants, irrespective of the presence of symptoms, were assayed by ELISA for the presence of TSWV. The percent infection of inoculated plants was calculated based on detection of TSWV by ELISA. Data were analyzed by ANOVA or GLM procedures of SAS (SAS Version 5, SAS Institute, Cary, NC). Significant differences were determined by Duncan's multiple range test at $P=0.05(17,21)$.

\section{RESULTS}

Initial attempts of sap transmission to peanut. Inoculation of 8-day-old peanut plant with inoculum prepared from tender symptomatic tobacco leaves resulted in $54.1 \%(\mathrm{~N}=24)$ transmission; tobacco leaves without symptoms resulted in $20 \%$ $(\mathrm{N}=25)$ transmission; and mature symptomatic tobacco leaves resulted in $16.6 \%$ $(\mathrm{N}=30)$ transmission by 10 to 15 DPI. Inoculated plants initially produced chlorotic spots on emerging quadrifoliates. Later, mosaic, ring spots, concentric rings, and necrotic spots developed. Infected plants were severely stunted compared with noninoculated control plants. Both leaves and roots of the inoculated plants were tested by ELISA. All the symptomatic plants were TSWV positive, and 10 to $12 \%$ of the asymptomatic plants showed the presence of TSWV in the roots but not in the leaves.

Methods of sap application. The rubbing method of inoculation resulted in 70 to $100 \%$ transmission by 6 to 10 DPI. Inoculation by pricking alone resulted in minimum $10 \%$ to maximum $60 \%$ transmission by 8 to 11 DPI. Rubbing and pricking together resulted in 90 to $100 \%$ transmission by 6 to 10 DPI (Table 1).

Effect of antioxidants and abrasives on transmission. One hundred percent of inoculated plants produced symptoms at 5 to 7 DPI when inoculum was prepared in the buffer containing both antioxidants, $\mathrm{Na}_{2} \mathrm{SO}_{3}$, and mercaptoethnol. At this time, none of the plants showed symptoms when inoculum was prepared with sterilized distilled water, and only $14.1 \%$ (average of $12.5,10$, and $20 \%$ in the three trials) and 50\% (average of 50, 40 , and $60 \%$ in the three trials) of plants produced symptoms when inocula were prepared with only buffer (no antioxidants) and with buffer containing only $\mathrm{Na}_{2} \mathrm{SO}_{3}$, respectively (data not shown). At 10 DPI, the final rate of transmission increased to $11.6 \%$ (average of 25, 10, and $0 \%$ in the three trials), $28.3 \%$ (average of 25,40 , and $20 \%$ in the three trials), and $75 \%$ (average of 75,70 , and $80 \%$ in the three trials) with water, 
buffer, and buffer containing $\mathrm{Na}_{2} \mathrm{SO}_{3}$, respectively (Fig. 1A).

Use of Carborundum alone as an abrasive gave fewer infected plants in each of the three trials, resulting in a lower transmission rate of $14.1 \%$ (average of $12.5,10$, and $20 \%$ in the three trials). When only Celite was used in the inoculum, a significantly higher transmission rate of $85.8 \%$ (average of 87.5, 80, and 90\% in the three trials) was achieved. Use of both Carborundum and Celite together resulted in infection of $96.6 \%$ (average of 100, 90, and $100 \%$ in the three trials) of the inoculated plants (Fig. 1B).

Growth stage and susceptibility of peanut. When seedlings were inoculated before opening of lamina at 5 DAP, $87.5 \%$ (average of $87.5,100$, and $75 \%$ in the three trials) of plants were infected. At 6 to 7 DAP, lamina of the first pair of quadrifoliate opened, and inoculation at this stage resulted in transmission rate of $95.8 \%$ (average of 87.5, 100, and $100 \%$ in the three trials). At 15 DAP, before flowering, 75\% (average of 75, 62.5, and $87.5 \%$ in the three trials) of plants were infected. At 35 DAP, after flowering stage, rate of transmission significantly declined to $25 \%$ (average of 0,50 , and $25 \%$ in the three trials) (Fig. 2A).

The average incubation period of TSWV in plants increased with the age of plants inoculated (Fig. 2B). When plants were inoculated with folded lamina (5 DAP), symptoms started developing in the majority (50 to $75 \%$ ) of inoculated plants by 4 to 6 DPI and in the rest of the plants (as mentioned above) by 6 to 7 DPI. In the three inoculation trials of 5-day-old plants, an average incubation period of 5.6 days was required (Fig. 2B) for the final incidence of $87.5 \%$ infected plants. When inoculation was done after opening lamina, at 6 to 7 DAP, 50 to $60 \%$ of the inoculated plants developed symptoms at $6 \mathrm{DPI}$, and by 10 DPI, the remaining plants produced symptoms. The average incubation period of 8.6 days was required (Fig. 2B) in the case of 6- to 7-day-old plants for the final incidence of $95.8 \%$ infected plants. At preflowering stage (15 DAP), fewer plants (12.5 to $37.5 \%$ ) produced symptoms at 6 to $7 \mathrm{DPI}$, and the remaining plants produced symptoms by 15 DPI. Symptoms in the plants inoculated after flowering stage (35 DAP) were less prominent (a few chlorotic spots), and it took a longer time of 18 to 22 days to develop. The average incubation periods of 15 and 20 days were taken by 15- and 35-day-old plants (Fig. 2 B) for the final incidence of 75 and $25 \%$ infected plants, respectively.

Inoculation from different sources. The transmission rates obtained from infected fresh, partially dry, and lyophilized tissues from different host plants are presented in Table 2. Fresh samples of peanut (leaves, roots, and whole plants), tobacco, and tomato leaves gave 91.6 to $100 \%$ transmission, whereas partially dried pea- nut plants gave $10 \%$ transmission and lyophilized peanut tissue was not infectious.

\section{DISCUSSION}

For sap transmission of plant viruses, the common variables are the inoculum source, buffer composition, additives used

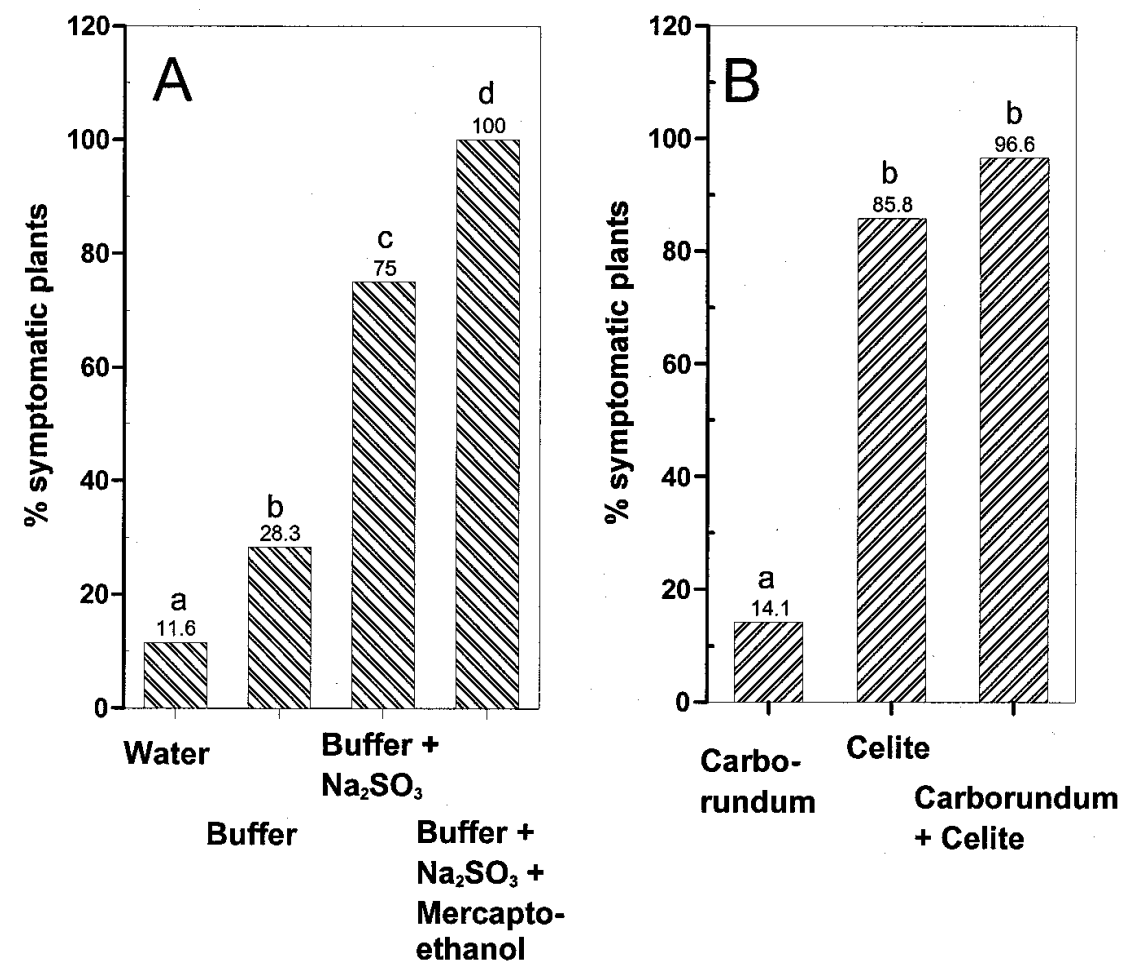

Fig. 1. Effect of $\mathbf{A}$, antioxidants, and $\mathbf{B}$, abrasives on the rate of transmission of Tomato spotted wilt virus from peanut to peanut. Bars represent average transmission from three trials at 10 days postinoculation. Bars marked with the same letter are not significantly different from each other at $P$ $=0.05$ according to Duncan's multiple range test.
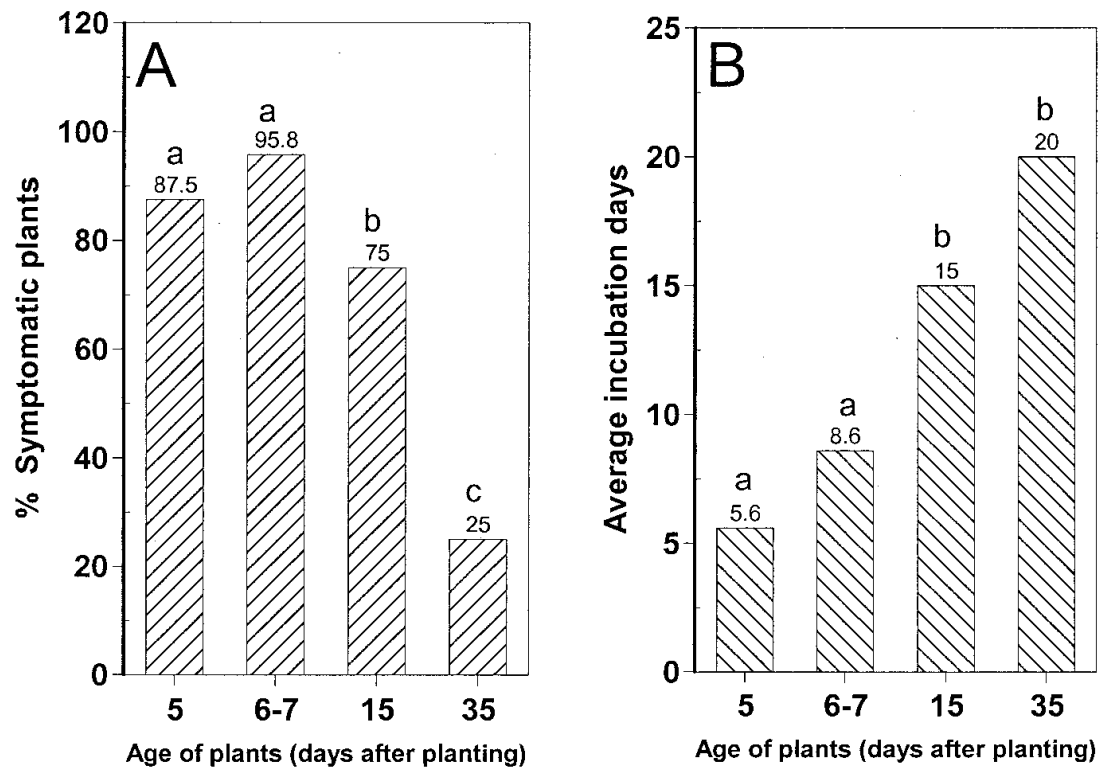

Fig. 2. Susceptibility of peanut to Tomato spotted wilt virus (TSWV) at different stages of plant growth: A, rate of transmission; $\mathbf{B}$, incubation days (time taken for symptom expression after inoculation). Percent transmission values recorded at 5.6, 8.6, 15, and 20 days postinoculation as indicated in $\mathbf{B}$ are means from three trials, and incubation days are the average days required to reach the final incidence presented in A. Bars marked with the same letter are not significantly different from each other at $P=0.05$ according to Duncan's multiple range test. 
dusted with Carborundum and were successful in achieving transmission 4 to 5 weeks after inoculation (transmission rate was not reported). They reported that mechanical transmission of TSWV could be difficult due to its instability (11). Dubern et al. (7) reported that TSWV occurring on peanut in Senegal was impossible to transmit mechanically from peanut to peanut. Nome et al. (14) and Pereira (16) also found that it was very difficult to infect peanut systemically with TSWV by mechanical inoculation. Clemente et al. (3) tested mechanical inoculation efficiency of TSWV from infected $N$. benthamiana to peanut and reported that $81 \%$ of inoculated plants were infected at 21 DPI. Hoffmann et al. (12) achieved a higher transmission rate 15 to 21 DPI in several peanut cultivars after mechanical inoculation of TSWV from infected $N$. benthamiana. It was generally accepted that mechanical transmission of TSWV from peanut to peanut was relatively difficult, resulting in a significant number of "escapes" $(7,11,14,16)$. As a result, available protocols suggested using Nicotiana benthamiana as a source for inoculating peanut. Other suggested critical factors for efficient mechanical inoculation were light intensity (3) and "dark treatment" of test plants (16). In the present study, we found various factors influencing mechanical inoculation of TSWV to peanut, such as growth environment, use of a combination of antioxidants and abrasives, plant growth stages, and the source of inoculum.

In the greenhouse, sap inoculation using field collected tobacco tissue of different maturity stages showed that the tender symptomatic tobacco leaves were a superior source of inoculum. Comparison of TSWV transmission from tobacco to peanut in greenhouse versus growth chamber showed that a maximum rate of transmission achieved in the greenhouse was $66.6 \%$ $(\mathrm{N}=15)$ at $15 \mathrm{DPI}$, whereas in growth chamber $100 \%(\mathrm{~N}=17)$ transmission was achieved by 10 DPI (data not shown). A lower rate of transmission in the greenhouse could be due to higher greenhouse temperature $\left(45^{\circ} \mathrm{C}\right.$ daily maximum). Inoculation in the growth chamber not only helped improve the rate of transmission but also reduced the time required for symptom expression.

In preliminary tests, application of sap on peanut lamina was tested by rubbing with a cotton swab, finger and pestle, and only cotton swab was found effective (data not shown). At 5 to 7 DAP, peanut lamina are small, and rubbing leaves with a cotton swab was more practical. The most tender leaves in the shoots were folded and not available due to the presence of sheaths at the base of petiole. To make inoculum accessible to the tender tissue, pricking was done in the main shoot and the two auxiliary shoots at the base of the cotyledons. When rubbing and pricking were used in combination, the rate of transmission approached $100 \%$ (Table 1).

Use of $\mathrm{Na}_{2} \mathrm{SO}_{3}$ and mercaptoethanol together in the extraction buffer also improved the transmission rate. The surface of peanut lamina is hydrophobic due to a wax layer, and mercaptoethanol may have improved the accessibility of the inoculum to the tissue. Use of mercaptoethanol was found to be superior to other antioxidants for sap transmission of Peanut bud necrosis virus (9). Carborundum is a commonly used abrasive for the sap transmission of plant viruses. Peanut lamina is not as soft as those of some solanaceous host species. To ensure more sublethal injury and to overcome the physical barrier on the lamina, both Celite and Carborundum were used. The data presented in Figure 1B showed that Celite was superior to Carborundum for TSWV transmission from peanut to peanut. Gentle rubbing of inoculum with the two abrasives did not cause much damage to the assay plants.
In the growth chamber, peanut seed germinated at 3 to 4 DAP. At 5 DAP, green folded leaves emerged, at 6 to 7 DAP the first pair of quadrifoliates were fully expanded, and later on, the lamina became dark green and mature. The rates of transmission at the seedling stage, before (5 DAP) and after (6 to 7 DAP) opening of the first pair of quadrifoliates, were found to be similarly higher than those at later stages. Before opening of the lamina, the plants were tender, but application of sap at this stage was not convenient due to their small size. With the lamina expanded, it was easier to apply the inoculum by rubbing, and a higher transmission rate was achieved at this stage. Therefore, 6- to 7day-old peanut plants were found to be ideal for mechanical inoculation.

In preliminary tests, we observed that inoculation of older peanut plants resulted in lower transmission rates, whereas higher rates of transmission were achieved when lower leaves were removed and the topmost quadrifoliate was inoculated (data not presented). Therefore, the susceptibility of peanut at older stage (pre- and post flowering stages) was evaluated by inoculating the top quadrifoliate after removing all the lower leaves. Infection at early stages of growth produced severely stunted plants, whereas inoculation at pre- or post flowering stages did not cause obvious reduction in plant height (data not shown). The rate of transmission and average incubation days presented in Figure 2 showed that peanut plants should be tested for TSWV infection by mechanical inoculation after emergence of seedlings at 5 to 7 DAP.

Evaluation of several factors affecting the sap transmission of TSWV to peanut resulted in development of a highly efficient protocol using infected tissue from different host plants such as peanut, tomato, and tobacco. In the present study, we used a single isolate of TSWV to evaluate the inoculation procedure. Transmission

Table 2. Sap inoculation of Tomato spotted wilt virus from different sources to peanut

\begin{tabular}{|c|c|c|c|c|c|}
\hline \multirow[b]{2}{*}{ Source of inoculum ${ }^{v}$} & \multicolumn{3}{|c|}{ No. symptomatic/no. inoculated ${ }^{w}$} & \multirow{2}{*}{$\begin{array}{c}\text { Average } \\
\% \text { transmission } \\
\end{array}$} & \multirow{2}{*}{$\begin{array}{l}\text { Days post- } \\
\text { inoculation }\end{array}$} \\
\hline & $\mathbf{I}^{\mathbf{x}}$ & II & III & & \\
\hline \multicolumn{6}{|l|}{ Fresh tissue } \\
\hline Tobacco leaves from field & $8 / 8$ & $8 / 10$ & $7 / 6$ & $95 \mathrm{a}$ & $5-10$ \\
\hline Whole peanut plant (15 DPI) from growth chamber & $10 / 10$ & $10 / 10$ & $10 / 10$ & $100 \mathrm{a}$ & $5-10$ \\
\hline Peanut leaves from growth chamber & $3 / 3$ & $5 / 6$ & $-\mathrm{z}$ & $91.6 \mathrm{a}$ & $7-10$ \\
\hline Peanut roots from infected plant in growth chamber & $5 / 5$ & $6 / 6$ & - & $100 \mathrm{a}$ & $7-8$ \\
\hline Tomato leaves from growth chamber & $5 / 5$ & $6 / 6$ & - & $100 \mathrm{a}$ & $7-12$ \\
\hline \multicolumn{6}{|l|}{ Partially dry tissue } \\
\hline $\begin{array}{l}\text { Whole infected peanut plant (15 DPI) stored at } 4^{\circ} \mathrm{C} \\
\text { for } 14 \text { days }\end{array}$ & $1 / 10$ & $1 / 10$ & - & $10 \mathrm{~b}$ & 10 \\
\hline \multicolumn{6}{|l|}{ Lyophilized tissue } \\
\hline Whole peanut plant from growth chamber 30 DPI & $0 / 10$ & $0 / 6$ & $0 / 6$ & 0 & 0 \\
\hline Peanut root from field dried 2 years ago & $0 / 12$ & $0 / 5$ & - & 0 & 0 \\
\hline Tobacco leaves from field dried 1 year ago & $0 / 11$ & $0 / 5$ & _ & 0 & 0 \\
\hline
\end{tabular}

$\overline{\mathrm{v}}$ Inoculum was prepared by grinding $2 \mathrm{~g}$ of tissue from an infected plant in $12 \mathrm{ml}$ of $0.1 \mathrm{M}$ phosphate buffer, $\mathrm{pH} 7.0$, containing $0.2 \% \mathrm{Na}_{2} \mathrm{SO}_{3}$ and $0.01 \mathrm{M}$ mercaptoethanol.

${ }^{\text {w }}$ Plants (5 to 7 days old) were inoculated by pricking and rubbing method using both Carborundum (2\%) and Celite (1\%) in the inocula.

${ }^{\mathrm{x}}$ Inoculation trials.

y Values in a column marked with the same letter are not significantly different from each other at $P=0.05$ according to Duncan's multiple range test.

${ }^{z}$ Not done. 
variability may exist among the isolates originating from different places and different plant species, and the present procedure has not been examined for any other TSWV isolates. The inoculation methods described here would help in rapid evaluation of peanut breeding linesgerm plasm for the source of resistance, which will eventually accelerate the breeding program for developing TSWV-resistant cultivars.

\section{ACKNOWLEDGMENTS}

This work was supported in part by funding from the Georgia Agricultural Commodity Commission for Peanut and USDA-CSREES Special Grant (99-34412-7415). B. Mandal is supported by a post-doctoral fellowship from USDA-CSREES Special Grant (99-34412-7415).

\section{LITERATURE CITED}

1. Black, M. C., Lumus, P. F., Smith, D. H., and Demski, J. W. 1986. An epidemic of spotted wilt disease in south Texas peanut in 1985. (Abstr.) Proc. Am. Peanut Res. Educ. Soc. 18:58.

2. Brown, S., Todd, J., Culbreath, A., Baldwin, J., Bassly, J., and Pappu, H. 2000. Tomato spotted wilt of peanut: Identifying and avoiding high-risk situations. Univ. Ga. Coop. Ext. Serv. Bull. 1165 .

3. Clemente, T. E., Weissinger, A. K., and Beute, M. K. 1990. Mechanical inoculation of tomato spotted wilt virus on peanut. Proc. Am. Peanut Res. Educ. Soc. 22:27.

4. Culbreath, A. K., Todd, J. W., Brown, S. L., Baldwin, J. A., and Pappu, H. 1999. A genetic and cultural "package" for management of to- mato spotted wilt virus in peanut. Biol. Cultural Tests 14:1-8.

5. Culbreath, A. K., Todd, J. W., Gorbet, D. W., Brown, S. L., Baldwin, J. A., Pappu, H. R., Holbrook, C. C., and Shokes, F. M. 1999. Response of early, medium, and late maturing peanut breeding lines to field epidemics of tomato spotted wilt. Peanut Sci. 26:100-106.

6. Culbreath, A. K., Todd, J. W., Gorbet, D. W., Brown, S. L., Baldwin, J. A., Pappu, H. R., and Shokes, F. M. Reaction of peanut cultivars to spotted wilt. Peanut Sci. In press.

7. Dubern, J., Huguenot, C., and Dollet, M. 1987. Tomato spotted wilt virus in Senegal? (Abstr.) Proc. Am. Peanut Res. Educ. Soc. 19:30.

8. German, T. L., Ullman, D. E., and Moyer, J. W. 1992. Tospovirus: Diagnosis, molecular biology, phylogeny, and vector relationships. Annu. Rev. Phytopathol. 30:315-384.

9. Ghanekar, A. M., Reddy, D. V. R., Iizuka, N., Amin, P. W., and Gibbons, R. W. 1979. Bud necrosis of groundnut (Arachis hypogaea) in India caused by tomato spotted wilt virus. Ann. Appl. Biol. 93:173-179.

10. Hagan, A. K., Weeks, J. R., French, J. C., Gudauskas, R. T., Mullen, J. M., Gazaway, W. S., and Shelby, R. 1990. Tomato spotted wilt virus in peanut in Alabama. Plant Dis. 74:615.

11. Halliwell, R. S., and Philley, G. 1974. Spotted wilt of peanut in Texas. Plant Dis. Rep. 58:2325.

12. Hoffmann, K., Geske, S. M., and Moyer, J. W. 1998. Pathogenesis of tomato spotted wilt virus in peanut plants dually infected with peanut mottle virus. Plant Dis.82:610-614.

13. Moyer, J. W. 1999. Tospoviruses (Bunyaviridae). Pages 1803-1807 in: Encyclopedia of Virology. A. Granoff and R. G. Webster, eds. Academic Press, San Diego, CA.

14. Nome, S. F., Giorda, L. M., Truol, G., de
Izaurralde, and Laguna, I. G. 1985. Necrosis del brot del mani (Arachis hypogaea L.) causada por el virus de la marchitez manchada del timate (tomato spotted wilt virus) en Argentina. IDIA 433/436:29-33.

15. Pappu, H. R. 1997. Management of emerging virus threats of crops: Impact of biotechnology in controlling tospoviruses. Biotechnol. Dev. Monitor 31:14-17.

16. Pereira, M. J. 1993. Tomato spotted wilt virus in peanut (Arachis hypogea L.): Screening technique and assessment of genetic resistance levels. M.S. thesis. University of Florida, Gainesville.

17. Steel, R. G. D., and Torrie, J. H. 1960. Principles and Procedures of Statistics. McGraw-Hill Book Co., New York.

18. Thompson, S. S., and Brown, S. L. 1990. Survey for tomato spotted wilt disease. Georgia Peanut Research-Extension Report. Coop. Res.-Ext. Publ. 2.

19. Todd, J. W., Culbreath, A. K., and Brown, S L. 1996. Dynamics of vector populations and progress of spotted wilt disease relative to insecticide use in peanut. Acta Hortic. 431:483-490.

20. Todd, J. W., Culbreath, A. K., Chamberlin, J. R., Beshear, R. J., and Mullinix, B. G. 1995. Colonization and population dynamics of thrips in peanuts in the southern United States. Pages 453-460 in: Thrips Biology and Management. B. L. Parker, M. Skinner, and T. Lewis, eds. Plenum Press, New York.

21. Waller, R. A., and Duncan, D. B. 1969. A Bayes rule for symmetric multiple comparison problem. J. Am. Stat. Assoc. 64:1484-1499.

22. Williams-Woodward, J. L. 2000. 1999 Georgia plant disease loss estimates. Univ. Ga. Crop Ext. Serv. Publ. Path 99-002. 